\title{
ECONOMY
}

\section{ПРИМЕНЕНИЕ НЕЧЕТКОЙ ЛОГИКИ ДЛЯ АНАЛИЗА РИСКОВ ИНВЕСТИЦИОННЫХ ПРОЕКТОВ. (НА ПРИМЕРЕ ЗАГОТОВИТЕЛЬНОГО ПРОИЗВОДСТВА МАШИНОСТРОИТЕЛЬНОЙ ПРОМЫШЛЕННОСТИ)}

\author{
Э. А. Алиев, \\ к.э.н., Азербайджанский Государственный Университет Нефти и Промышленности \\ Азербайджан
}

DOI: https://doi.org/10.31435/rsglobal_ws/28022020/6930

\section{ARTICLE INFO}

Received: 09 December 2019

Accepted: 13 February 2020

Published: 28 February 2020

\section{KEYWORDS}

development of procurement, uncertainty, risk, risk-generating factors, environmental risks, risk assessment, classification of risk assessment methods, risk assessment methods, fuzzy logic, fuzzy logical conclusion.

\begin{abstract}
The article considers the problem of risk assessment in the construction project of procurement. The classification of risk assessment methods based on the completeness of information available to the researcher is given. Summary of essence simulation methods, statistical method, sensitivity analysis method, landscaping decision method, expert method and approach based on the use of fuzzy logic. A more detailed description of the assessment of environmental risks using a method based on the use of a fuzzy logic apparatus is given.
\end{abstract}

Citation: Э. А. Алиев. (2020) Primenenie Nechetkoj Logiki dlya Analiza Riskov Investicionnyh Proektov. (na Primere Zagotovitel'nogo Proizvodstva Mashinostroitel'noj Promyshlennosti). World Science. 2(54), Vol.1. doi: 10.31435/rsglobal_ws/28022020/6930

Copyright: (C) 2020 Э. А. Алиев. This is an open-access article distributed under the terms of the Creative Commons Attribution License (CC BY). The use, distribution or reproduction in other forums is permitted, provided the original author(s) or licensor are credited and that the original publication in this journal is cited, in accordance with accepted academic practice. No use, distribution or reproduction is permitted which does not comply with these terms.

Ведение. Для развития машиностроительного комплекса в республике в настоящее время является основы заготовительные производства. В структуре заготовок (литых, сварных, кованных, штампованных), потребляемых в машиностроении и металлообработке, отливки занимают около $42 \%$. Литейная продукция используется почти во всех отраслях народного хозяйства. Развития литейного производства зависит от эффективной работы заготовительных предприятий. Снижение себестоимость и качество изготавливаемых изделий машиностроительных отраслей народного хозяйства зависят одновременно успехи и эффективной работы заготовительного производства. Поэтому ценообразование на продукции заготовительного производства во многом обусловлено технико-экономическими особенностями производства и спецификой продукции.

Высокие темпы развития машиностроения требуют значительного увеличения объема производства заготовок, повышения их качества, изменения структуры выпуска. Основные задачи развития заготовительного производства входят:

- ускорение роста производительности труда на основе создания и внедрения нового высокопроизводительного оборудования, системы машин, комплексной механизации и автоматизации производственных процессов и системы управления;

- повышение качества, надежности, точности и чистоты поверхности отливок с оптимальным их приближением к размерам готовых деталей; 
· сокращение объема механической обработки, снижение на 15-20\% массы заготовок и деталей путем внедрения прогрессивных сплавов и технологических процессов;

· дальнейшее совершенствование структуры заготовительного производства в направлении повышения удельного веса отливок из высококачественных чугунов и сплавов с улучшенными физико-механическими свойствами;

· углубление специализации и концентрации заготовительного производства. После развала Советского Союза в Азербайджане не созданы не одного развитого заготовительного производства. Все действующие заводы и цеха работают по старым методами и это отрицательно действует на развитие машиностроительного производства.

По-нашему мнению учитывая потребности машиностроительных отраслей необходимо проектировать строительства заготовительного производства.

На текущий момент стратегия развития машиностроения предусматривает реализацию различных проектирование производства: планируется строительство завода по производству стальных, чугунных и цветных отливки разными способами, по изготовление поковки, штамповки, металлоконструкции и модельного производства. При реализации проектов подобного плана наиболее важным моментом считается минимизация негативного влияния создаваемых объектов на окружающую среду и человека.

При разработке проектов принятие каких-либо решений осуществляется в условиях неопределенности. Неопределенность прогнозируемых результатов приводит к возникновению риска того, что поставленные цели могут быть достигнуты лишь частично или не достигнуты. Поэтому очень важно предусмотреть изменение факторов и условий, которые могут оказать негативное влияние на проект.

В проектах развития заготовительного производства для машиностроения особенно важно оценить риски, связанные с экологической безопасностью:

- загрязнение окружающей среды в ходе производственной деятельности;

- аварийные риски с экологическими последствиями;

- риски ухудшения здоровья населения и персонала;

• риски ухудшения социального и культурного благополучия людей.

\section{1. Выбор и обоснование методов оценки рисков проект строительства} заготовительного производства.

Все факторы рисков можно разделить на две группы: определенные и неопределенные.

К определенным факторам относят переменные, значения которых известны с некоторой требуемой точностью. К неопределённому фактору относят переменные, о значениях которых в реальном процессе исследователь осведомлен не полностью. Порожденная неопределенностью возможность того, что при осуществлении выбранного варианта решения поставленная цель не достигается, называется риском [1]. Обычно риск рассматривают как сочетание двух компонент - вероятности наступления события и величины ущерба, которое может принести наступление события. В вопросе об оценке рисков различных проектов нет методологической однозначности. Обычно все методы делят на две категории: качественные и количественные, - но это деление весьма условно. Мы будем рассматривать классификацию методов в зависимости от полноты информации, имеющейся у исследователя. Согласно этому критерию методы оценки рисков можно объединить в три группы: методы, применяемые в условиях определенности; методы, применяемые в условиях частичной неопределенности; методы, применяемые в условиях полной неопределенности [2, 4, 6-8] в условиях определенности применяются расчетно-аналитические методы. Они используются при расчете показателей риска в основном по данным бухгалтерского учета.

В условиях частичной неопределенности риск рассматривается как вероятностная категория, поэтому в этих случаях целесообразно использовать вероятностные и статистические методы оценки риска. Сюда можно отнести статистический метод, имитационное моделирование, анализ чувствительности. Статистический метод применяется в случае наличия достаточной статистической базы по искам данного вида. Данный метод позволяет оценить частоту проявления данного вида рисков, вероятность наступления рисковой ситуации, определить величину возможных потерь. Статистические методы оценивания уровня риска дают высокую степень достоверности лишь при достаточно большом объеме статистической информации.

При использовании метода имитационного моделирования генерируется множество возможных комбинаций факторов проекта с учетом их вероятностного распределения. Метод 
имитационного моделирования дает точную и четкую оценку рискам проекта. Он позволяет учесть максимально возможное число факторов внешней среды. Недостатками этого метода являются:

- трудность в определении вида вероятностного распределения для исследуемого параметра;

- некоррелированность параметров, что сильно усложняет модель, и не всегда возможно оценить зависимость между параметрами;

- исследование модели возможно только с помощью вычислительной техники;

- при разработке реальных моделей может возникнуть необходимость привлечения специалистов или научных консультантов со стороны.

При использовании метода анализа чувствительности риск рассматривается как степень чувствительности результирующих показателей реализации проекта к изменению условий функционирования. Анализ начинается с установления базового значения результирующего показателя при фиксированных значениях параметров, которые могут влиять на результат оценки проекта. Затем производится изменение одного из факторов при неизменности остальных и рассчитывается процентное изменение. Метод древовидная применяется в тех ситуациях, когда решения, принимаемые в каждый момент времени, сильно зависят от предыдущих решений и в свою очередь определяют сценарии дальнейшего развития событий. Ограничением использования данного метода является то, что проект должен иметь обозримое или разумное число вариантов развития. В условиях полной неопределенности могут быть использованы экспертные методы оценки риска, а также методы, основанные на использовании аппарата теории нечетких множеств. Экспертный метод представляет собой обработку оценок экспертов по каждому виду рисков и определение интегрального уровня риска. В целях получения более объективной оценки специалисты, проводящие экспертизу, должны обладать полным спектром информации об оцениваемом проекте. После определения вероятностей все показатели сводятся к интегральной оценке. Наиболее часто для этого используется подход, предполагающий ранжирование рисков по степени приоритетности и определение весовых коэффициентов в соответствии со значимостью этих рисков. Положительными сторонами метода являются простота расчетов и отсутствие необходимости в точной информации. Нечеткий логический вывод для оценки рисков включает в себя следующие основные этапы: идентификацию рисков, заполнение базы правил, преобразование входных переменных преобразование в нечеткую форму, нечеткий логический вывод и получение количественного значения величины риска. [10].

Недостатки метода - наличие некоторой субъективности в оценках эксперта и трудности в поиске высококвалифицированных специалистов (инженеров по знаниям). Также при использовании нечеткого вывода база правил может получаться достаточно объемной.

2.Применение нечеткой логики оценке риска строительства заготовительного производства.

Не существует универсального метода, который позволил бы дать точную оценку рисков. При оценке экологических рисков применение вероятностных и статистических методов может быть ограничено вследствие отсутствия статистических данных или сложностей в подборе вида распределения исследуемой величины.

Использование аппарата нечетких множеств позволяет оперировать качественными переменными, учитывать скрытые закономерности и нелинейные зависимости между данными.

Рассмотрим подробнее основные этапы нечеткого вывода. Для примера возьмем оценку риска загрязнения окружающей среды. В качестве факторов угрозы загрязнения окружающей среды в ходе производственной деятельности были выделены:

- загрязненность почвы;

- загрязненность атмосферы;

- загрязненность водной среды.

База правил систем нечеткого вывода есть формальное представление эмпирических знаний эксперта в рассматриваемой предметной области. В этих системах используются правила нечетких продукций, в которых условия и заключения сформулированы в терминах нечетких лингвистических высказываний. Для риска загрязнения окружающей среды база правил могла бы выглядеть следующим образом:

«IF<загрязненность атмосферы $=$ очень низкая $>\&<$ загрязненность почвы $=$ очень низкая $>\&<$ загрязненность водной среды $=$ очень низкая $>$ THEN $<$ риск $=$ очень низкий $>$ »;

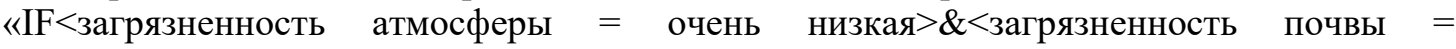
низкая $>\&<$ загрязненность водной среды $=$ низкая $>$ THEN $<$ риск $=$ очень низкий $>\gg$; 
«IF<загрязненность атмосферы $=$ очень высокая $>\&<$ загрязненность почвы $=$ высокая $>\&<$ загрязненность водной среды = высокая $>$ THEN $<$ риск $=$ очень высокий $>$ ».

Здесь факторы риска «загрязненность почвы», «загрязненность атмосферы», «загрязненность водной среды» являются входными переменными, а «риск» - выходной переменной. На этапе преобразования в нечеткую форму числовое значение входного параметра преобразуется в нечеткую форму, то есть находится функция принадлежности для данного параметра. Например, для параметра «Загрязненность атмосферы», оцененного в значение 20 по стобалльной шкале.

На этапах агрегирования и активизации определяется степень истинности каждого и подзаключений по каждому из правил систем нечеткого вывода, и далее полученные нечеткие подмножества каждой выходной переменной объединяются в одно нечеткое подмножества.

На этапе вычисление количественного значения полученные выходные переменные преобразуются в количественные значения по одному из методов вычисление количественного значения. Чаще всего для этого используется метод центра тяжести [9]. Вычисление количественного значения таким образом, оценка экологических рисков в проекте развития заготовительного производства является одним из наиболее важных моментов при разработке проекта. Для рисков ущерба состоянию окружающей среды и людей наиболее подходящим является метод, основанный на использовании аппарата нечеткой логики, который позволяет получать оценки в условиях неопределенности или при наличии слабоформализованной информации.

Выводы. Таким образом, оценка экологических рисков в проектах развития заготовительного производства является одним из наиболее важных моментов при разработке проекта. Для рисков ущерба состоянию окружающей среды и людей наиболее подходящим является метод, основанный на использовании аппарата нечеткой логики, который позволяет получать оценки в условиях неопределенности или при наличии слабоформализованной информации.

Кроме того, разработанная нечеткая продукционная модель и система поддержки принятия решений позволяет инвестиционно-строительных проектов проводить планирование действий по снижению риска проектов путем анализа ситуаций по схеме «Если - То». Оценка различных воздействий на процесс проектирования и реализацию строительных объектов позволяет целенаправленно снижать риски на различных стадиях жизненного цикла проекта. Полученные оценки риска на основе механизма нечеткой логики позволяют учитывать как качество входной информации, так и надежность информации от экспертов. Механизм обладает широкими возможностями и позволяет адаптировать его к имеющимся моделям управления рисками, а также модифицировать с учетом различных условий реализации ИСП.

\section{ЛИТЕРАТУРА}

1. Качалов Р. М. Управление хозяйственным риском. М.: Наука, 2002.

2. Лаптева Н. А. Оценка рисков при реализации инвестиционно-строительного проекта на примере бизнес-центра// Magazineofcivilengineering. 2011. № 2.

3. Мурзин А. Д. Эколого-экономические риски инвестиционно-строительных проектов развития городских территорий // Всероссийская конференция «Проблемы экономики и управления строительством в условиях экологически ориентированного развития».

4. Попова А. Ю. Оценка риска инвестиционного проекта. URL: http://ej.kubagro.ru/2006/03/07/

5. Проекты, реализуемые в Волгоградской области. URL: http://www.investvolgograd.ru/for_investors

6. Садовникова Н. П., Ермощенко А. К. Общие вопросы применения методологии имитационного моделирования для оценки эколого-экономической эффективности проектов градостроительной деятельности // Изв.ВолгГТУ. Сер. Актуальные проблемы управления, вычислительной техники и информатики в технических системах. Вып. 11: межвуз. сб. науч. ст. / ВолгГТУ. Волгоград, 2011. № 9.

7. Садовникова Н. П., Кузнецов М. С., Васильев С. А. Управление экологическими рисками проектов территориального развития // Интернет-вестник ВолгГАСУ. Сер. Строительная информатика. 2012. № 8 (24). URL: http://vestnik.vgasu.ru /attachments/SadovnikovaKusnetsov-2012_8\%2824\%29.pdf

8. Токаренко Г. С. Методы оценки рисков // Финансовый менеджмент. 2006. № 6.

9. Фиронова Е. Применение нечеткой логики для анализа рисков инвестиционных проектов. URL: http://ecsocman.hse.ru /data/152/124/1231/Fuzzytekstdlyasajta.doc@ Н. К. Усачева.

10. В. П. Самарай. Алгоритмы расчета вероятных рыночных цен на продукцию из цветных металлов и сплавов. Металл и Литье Украины № 5 (240). 2013. 